\title{
THE EFFECTS OF ACID PASSIVATION, TRICRESYL PHOSPHATE PRE-SOAK, AND UV/OZONE TREATMENT ON THE TRIBOLOGY OF PERFLUOROPOLYETHER-LUBRICATED 440C STAINLESS STEEL COUPLES
}

\author{
Bradley A. Shogrin \\ Case Western Reserve University \\ Cleveland, Ohio 44106 \\ William R. Jones, Jr. \\ National Aeronautics and Space Administration \\ Lewis Research Center \\ Cleveland, Ohio 44135 \\ and \\ Pilar Herrera-Fierro \\ Ohio Aerospace Institute \\ 22800 Cedar Point Road \\ Cleveland, Ohio 44142
}

\begin{abstract}
SUMMARY
The boundary-lubrication performance of perfluoropolyether (PFPE) thin films in the presence of passivated $440 \mathrm{C}$ stainless steel is presented. The study utilized a standard ball-on-disc tribometer. Stainless steel surfaces were passivated with one of four techniques: (1) submersion in a chromic acid bath for 30 min at $46{ }^{\circ} \mathrm{C}$, (2) submersion in a chromic acid bath for $60 \mathrm{~min}$ at $56^{\circ} \mathrm{C}$, (3) submersion in a tricresyl phosphate (TCP) bath for 2 days at $107^{\circ} \mathrm{C}$, or (4) UV/Ozone treated for $15 \mathrm{~min}$. After passivation, each disc had a $400 \AA$ film of PFPE (hexafluoropropene oxide) applied to it reproducibly ( \pm 20 percent) and uniformly ( \pm 15 percent) using a film deposition device. The lifetimes of these films were quantified by measuring the number of sliding wear cycles required to induce an increase in the friction coefficient from an initial value characteristic of the lubricated wear couple to a final, or failure value, characteristic of an unlubricated, unpassivated wear couple. The lubricated lifetime of the $440 \mathrm{C}$ couple was not altered as a result of the various passivation techniques. The resulting surface chemistry of each passivation technique was examined using x-ray photoelectron spectroscopy (XPS). It was found that chromic acid passivation altered the $\mathrm{Cr}$ to $\mathrm{Fe}$ ratio of the surface. TCP passivation resulted in a $\mathrm{FePO}_{4}$ layer on the surface, while UV/Ozone passivation only removed the carbonaceous contamination layer. None of the passivation techniques were found to dramatically increase the oxide film thickness.
\end{abstract}

\section{INTRODUCTION}

Pretreatment of instrument-bearing components with either a tricresyl phosphate (TCP) presoak (refs. 1 to 10 ) or a chromic acid passivation bath (refs. 2 and 4), has been performed for over 30 years. Indeed, it has repeatedly been shown that each of these pretreatment procedures improve the bearing's performance in lowspeed, boundary lubricated contacts (refs. 1, 2, 9, and 10). Over the years, each of these pretreatments has been incorporated in standard bearing component preconditioning procedures in an attempt to provide additional protection while it is under boundary-lubrication conditions (i.e. during startup and shutdown) (refs. 2 and 8). However, all known reports of improved boundary lubrication performance have utilized either mineral oils or synthetic esters. This is not surprising since the vast majority of TCP and chromic acid passivation qualifying research was performed in the 1960's, when these were the dominant classes of lubricants. These lubricant classes are vastly different than the perfluoropolyether class commonly used today. There has only been one study (ref. 27) that focused on the longevity of a TCP passivated surface lubricated with a PFPE, and none on chromic acid passivated surfaces. Wedeven et al. (ref. 27) concluded that TCP passivation had no effect on the longevity of the lubrication system. 
Perfluoropolyethers (PFPE's) have been the preferred liquid lubricants for space applications for over two decades because of their proven tribological performance and other attractive properties (ref. 11) such as low vapor pressure, low chemical reactivity, and wide liquid temperature range. These oils are used in such space mechanisms as actuators, antenna pointing mechanisms, filter wheels, gyroscopes, and scanning mirrors (refs. 12 and 13). However, there have been many incidents during which PFPE-lubricated space mechanisms have shown anomalous behavior (refs. 14 and 15). These anomalies are thought to be the result of PFPE degradation. In order to understand how various passivation techniques might affect the boundary-lubricating performance of PFPEs, it is first necessary to understand how PFPEs degrade.

A number of studies have focused on understanding and modeling the degradation of PFPE lubricants. Research has repeatedly shown that PFPE's degrade while in boundary-lubricated, sliding/rolling contact (refs. 16 to 21) and at elevated temperatures (refs. 22 to 25) losing their desirable properties, including lubricity. Although few models have been proposed to explain the observed degradation, it has been shown that the rate of degradation is dependent upon the surface chemistry of the substrate, and the presence and relative strength of Lewis acids substrates.

Kasai (ref. 22) has shown that the thermal catalytic degradation of a PFPE is dependent upon the strength of the Lewis acid present and has proposed a chemical degradation mechanism for PFPE's. He postulated a mechanism in which Lewis acids act as a catalyst that promotes an intramolecular disproportionation reaction which results in polymer-chain degradation.

Other static degradation studies, conducted to look at the effects of certain metals or metal alloys in the presence of particular PFPE's, have shown that PFPE degradation is highly dependent upon the chemistry of the substrate. For example, an unbranched PFPE lubricant showed more degradation at $288{ }^{\circ} \mathrm{C}$ in the presence of M-50 steel and Ti-4Al-4Mn than in contact with either pure titanium or pure aluminum (ref. 24).

Some studies have applied the concept of modifying one, or both of the surface chemistries by coating or ion implanting the surface(s), and observing the associated tribological characteristics. Carre (ref. 19) demonstrated that the PFPE boundary-lubricated wear life was increased by a factor of 5 to 10 by using TiN-coated $440 \mathrm{C}$ test specimens. TiC-coated $440 \mathrm{C}$ and $\mathrm{Si}_{3} \mathrm{~N}_{4}$ ceramic ball bearings have also been shown to have greater longevity compared to their $440 \mathrm{C}$ counterparts when PFPE lubricated (refs. 18 to 20). In Carré's studies (refs. 19 and 20) it was concluded that the hard coatings and ceramic material prevented the formation of Lewis acids, thus halting the Lewis acid-induced degradation of the PFPE. Shogrin et al. (ref. 26) demonstrated that implanting $440 \mathrm{C}$ substrates with either $\mathrm{Ti}$ with a carbon $\left(\mathrm{CH}_{4}\right)$ back pressure, or $\mathrm{Ti}$ without a carbon back pressure enhanced the lubricating lifetimes of the PFPE. It was concluded that the resulting microstructures inhibited the formation of reactive sites.

Yet another way to inhibit tribo-induced degradation of the lubricating PFPE may be to passivate the contacting surfaces. The passivated surfaces might inhibit the formation of Lewis acids in the presence of fluorinated oils, or decrease the relative availability of reactive sites on the surface, thus, extending the lubricated lifetime of the couple.

The objective of this work was to study the effect of various passivation techniques on the lubricatinglifetime of a PFPE-lubricated $440 \mathrm{C}$ stainless steel couple in sliding contact. The two passivation techniques mentioned, chromic acid passivation (similar to 2 and 4) and TCP (similar to 1 to 10 ), as well as a modified chromic acid passivation technique (which uses a higher temperature and a longer reaction time), and UV/Ozone treatment (ref. 30) will be studied. UV/Ozone treatment has been used to remove carbonaceous contamination from surfaces. A demonstration of their effectiveness in prolonging lubricity is sought rather than a detailed description of the associated chemical degradation mechanism(s).

\section{EXPERIMENTAL}

\section{Materials}

Discs and bearing balls made from $440 \mathrm{C}$ stainless steel (fully hardened) were used. The $440 \mathrm{C}$ discs were $17.5 \mathrm{~mm}(11 / 16 \mathrm{in}$.) in diameter and $4.76 \mathrm{~mm}$ (3/16 in.) thick. Each disc was polished to a mirror finish having an arithmetic roughness average, $R_{a}$, of $\sim 0.01 \mu \mathrm{m}$. The bearing balls were Grade 10 and had a diameter of $9.53 \pm 0.00102 \mathrm{~mm}(3 / 8 \mathrm{in} . \pm 0.00004 \mathrm{in}$.).

A variety of surface preparations were tested. A portion of the disc/ball pairs were tested unlubricated and untreated (unpassivated), while others were tested unlubricated after being treated (passivated). Still others (passivated and unpassivated) were tested after lubricating the disc. None of the bearing balls were lubricated prior to testing. Throughout this report the term "unpassivated" is used rather loosely. When used, it refers to pairs that have not been passivated or UV/Ozone treated. The lubricant used was a commercial 
perfluoropolyether (PFPE), based on hexafluoropropene oxide (HFPO). Typical properties of this PFPE are given in Table I.

\author{
Specimen Preparation
}

All disc/ball pairs were ultrasonically cleaned in hexane, acetone, and finally methanol for approximately ten minutes each. The pairs were then blown dry with nitrogen and promptly covered to minimize dust contamination. Disc/ball pairs that were not passivated and did not have PFPE applied to the disc were placed in a $\mathrm{N}_{2}$ atmosphere (R.H. $<2$ percent) at ambient temperature where they remained until tribo-tested. Unpassivated discs that had PFPE applied, were lubricated and then placed in a $\mathrm{N}_{2}$ atmosphere, with their accompanying unpassivated ball. Disc/ball pairs that were treated were done so using one of the four following procedures.

Chromic-Acid Passivation.-Clean disc/ball pairs were passivated in one of two ways using a solution consisting of $2.0 \mathrm{gm}$ sodium dichromate $\left(\mathrm{Na}_{2} \mathrm{Cr}_{2} \mathrm{O}_{7} \cdot 2 \mathrm{H}_{2} \mathrm{O}\right), 20 \mathrm{ml}$ concentrated nitric acid $\left(\mathrm{HNO}_{3}\right)$, and $80 \mathrm{ml}$ deionized $\mathrm{H}_{2} \mathrm{O}$. Specimens were immersed in the solution either for $30 \mathrm{~min} \pm 10 \mathrm{sec}$ while heated to $46 \pm 0.1{ }^{\circ} \mathrm{C}$, or for $60 \mathrm{~min} \pm 10 \mathrm{sec}$ while heated to $56 \pm 0.1{ }^{\circ} \mathrm{C}$. The samples were then removed and thoroughly rinsed using two successive deionized $\mathrm{H}_{2} \mathrm{O}$ baths. Samples were then blown dry with nitrogen and promptly covered.

Tricresyl Phosphate (TCP) Passivation.-Disc/ball pairs were immersed for $48 \mathrm{hr} \pm 5 \mathrm{~min}$ in neat tricresyl phosphate (TCP) heated to $107 \pm 0.1^{\circ} \mathrm{C}$. (The TCP was purchased in accordance with the requirements of TT-T-656b). The samples were then ultrasonically cleaned in hexane, acetone, and methanol for approximately $10 \mathrm{~min}$ each. Samples were then blown dry with nitrogen and promptly covered.

UV/Ozone Treatment.-Disc/ball pairs were UV/ozone treated for 15 min to remove carbonaceous contamination (ref. 30) which begins to reform immediately after this treatment.

Treated discs that did not have PFPE applied to them, and all treated bearing balls were placed in a dry $\mathrm{N}_{2}$ atmosphere where they remained until tribo-tested. Treated discs that had PFPE applied to them were lubricated (UV/ozone treated discs were lubricated within 5 min of treatment) and then placed in the same dry $\mathrm{N}_{2}$ environment.

XPS Analysis of Passivated Surfaces.-A disc passivated by each of the four techniques and a baseline disc (untreated) were analyzed using $\mathrm{X}$-ray photoelectron spectroscopy (XPS). The XPS analysis was done in a Vacuum Generator (VG) ESCALAB MkII system equipped with a $M g \mathbf{K}_{\alpha} \mathbf{x}$-rays ource. XPS analyzes the top several atomic layers of the sample providing both elemental and chemical state information. An area of $2 \times 5 \mathrm{~mm}^{2}$ was analyzed on each of the respective surfaces. Survey spectra, from 0 to $1200 \mathrm{eV}$ Binding Energy, were taken to determine which elements were present followed by high resolution energy windows for each of the major elements detected on the surface to determine their chemical state. There is typically a 5 to 10 percent error associated with the resulting calculated atomic concentrations.

\title{
Application of Lubricant Films by Deposition from a Solution
}

Thin film deposition was accomplished by using the apparatus shown in figure 1 . This is a derivative of the deposition process known as dipping. In this process, a specimen is lubricated by slowly withdrawing it at a constant speed from a solution of the fluid in a volatile solvent. As the solvent evaporates, a thin film of the nonvolatile fluid remains on the surface. In this procedure, both solution concentration and withdrawal speed govern the applied film thickness (ref. 31). For the apparatus used in this study, gravity driven solution flowed past the stationary specimen. The surface speed that the solution attained as it flowed past the specimen was approximately $0.8 \mathrm{~mm} / \mathrm{sec}$. Each lubricated disc was done so using a concentrations of $5.0 \mathrm{~g}$ of PFPE lubricant in $100 \mathrm{ml}$ of solvent (a perfluorinated cyclobutane).

\section{Lubricant Film Thickness Measurements}

The PFPE thickness on each disc was measured using an infrared microscope ( $\mu$-FTIR) in the reflectance mode using a Grazing Angle Objective (GAO) with a Mercury Cadmium Telluride (MCT) detector. The instrument's spectral resolution was $4 \mathrm{~cm}^{-1}$. A gold coated glass slide was used as the background. Absorbance as a function of wave number was determined for each film at three different radii on the disc's surface, approximately $120^{\circ}$ apart using an analysis spot diameter of $100 \mu \mathrm{m}$. 
Theoretical thin film optical calculations have been performed to model the PFPE film's behavior in the infrared spectral region (ref. 32). These results are plotted as absorbance of the $1313 \mathrm{~cm}^{-1}$ band as a function of film thickness, and shown in figure 2. After experimentally obtaining the absorbance of the $1313 \mathrm{~cm}^{-1} \mathrm{band}_{\text {, }}$ the corresponding film thickness was obtained using figure 2 .

The FDD apparatus produced PFPE film thicknesses of $\sim 400 \AA$. Lubricant uniformity across any one surface was \pm 15 percent. The error associated with surface-to-surface film thickness repeatability was \pm 20 percent.

\title{
Tribological Testing
}

Tribological testing of each disc/ball couple was performed on the fixed-ball-on-disc tribometer shown in figure 3. All tests were performed using a relative sliding speed of $0.05 \mathrm{~m} / \mathrm{s}$ and a $3-\mathrm{N}$ normal load which generated an initial Hertzian contact pressure of $\sim 0.69 \mathrm{GPa}$. All tests were run in dry $\mathrm{N}_{2}(<2$ percent $\mathrm{RH}$ ) at ambient temperature $\left(\sim 25^{\circ} \mathrm{C}\right)$. The friction force as a function of disc revolutions (cycles) was recorded for each test (one wear track).

After a test, the ball support fixture and ball were rotated to expose an unworn surface on the ball and the fixture was extended so the ball would contact the disc at a different radius. By doing this, three wear tracks, $1.59 \mathrm{~mm}(1 / 16 \mathrm{in}$.) apart, could be worn on each disc.

\section{RESULTS AND DISCUSSION}

\author{
Establishment of the Lubricant-Failure Criterion
}

Lubricant failure occurred when the friction coefficient increased from an initial low value to a value typical of an unlubricated, unpassivated disc/ball couple. When this failure occurred, it was argued that the protective layer(s) (applied lubricant, surface oxide, and/or additional passivation layer) either wore off, ruptured or broke down. Figure 4 shows the mean friction coefficient as a function of cycle number for three wear tracks on two separate unlubricated, unpassivated couples. Mean friction coefficient was the mean of the friction coefficients of the complete revolution over the indicated cycle. Typically, friction-coefficient fluctuations over a cycle were \pm 0.06 (maximum: \pm 0.15 ) about the mean. The mean friction coefficient data all lied between 0.63 and 0.8 . Thus, an increase in mean friction coefficient above 0.63 was indicative of failure and was defined as the failure limit. The number of rotational cycles that can be applied to the lubricant film on a wear track before the friction rised above the failure limit was the film's lubricating lifetime.

It was also important to know if the passivation process itself changed the failure limit, therefore, one disc passivated at each condition was tested unlubricated. Initially, the chromic-acid and TCP passivation samples exhibited lower mean friction coefficients $(0.26$ to 0.3$)$, but then rose near-linearly above the failure limit at different rates. The value of the TCP passivated surface continued to rise to $\sim 0.8$, where it then dropped to a value of $\sim 0.53$ in the course of one cycle, after which it again rose to failure and stayed. The UV/Ozone treated surfaces showed no improvements and behaved the same as the untreated samples depicted in figure 4 . Table II summarizes these data. The UV/Ozone treated results are not shown because no improvements were observed with this technique. In this table, the average values appear outside the parentheses, whereas the ranges are contained within the parentheses. These data suggest that both chromic-acid passivation techniques improved the friction coefficient for a brief time, whereas TCP passivation extended the low friction coefficient for an extended time.

\section{Lubricated Results}

Lubricated, unpassivated discs/ball couples were tested. A typical plot of mean friction coefficient vs. cycle number is shown in figure 5 . These particular data were taken from a disc with a $\sim 70 \AA$ HFPO film. The mean friction coefficient begins to rise from $\leq 0.3$ near 200 cycles and crosses the failure line of 0.63 at $\sim 370$ cycles (lubricant lifetime $=370$ cycles).

This general trend was typical for the samples used in this study. In these tests the maximum variation of the friction coefficient before it began to rise (here at $\sim 200$ cycles) was \pm 0.02 . This relatively small variation indicated that the entire wear track was uniformly experiencing the benefits of full boundary lubrication from the PFPE. After the initial rise, the variation of friction coefficient grew as the number of cycles increased until, at the failure limit, it typically had a variation of \pm 0.1 (maximum: \pm 0.20 , minimum: \pm 0.03 ).

As a test progressed, different locations on the wear track lost their lubricity at varying rates, which accounted for the spread in friction coefficient values seen over one cycle (indicated by the variation noted 
above). Although the rate of lubricity loss over the entire wear track varied, and the variation increased as the number of cycles increased, the mean friction coefficient continued to rise, signifying an overall loss of lubricity.

Beyond failure, variations of the friction coefficient over a rotational cycle, as well as the mean friction coefficient were sporadic. On some wear tracks, the mean friction coefficient dipped below the failure line after it had reached failure (rarely dipping below $\sim 0.4$ ). This decrease was caused by the rapid growth of the wear scar's width coming into contact with fresh, unused PFPE lubricant. This fresh lubricant decreased the friction coefficient before it too degraded, causing the mean friction coefficient to again rise past the failure limit. These sporadic variations were also considered an indicator of failure.

After performing a number of the tests, it was apparent that the lifetimes had a significant spread in their values for each of the unpassivated and passivated conditions. These spreads in lifetime appeared random, as they were not dependant upon either a particular disc or radius of wear track. Weibull statistics (ref. 33) were used to characterize these data.

The Weibull plot for the unpassivated disc/ball couples PFPE-lubricated is shown in figure 6. Each data point represents the lubricated lifetime of one wear track. The Median Rank Line represents the most probable failure history for the samples, that is, the fraction of a group of samples that can be expected to fail (i.e., exceed 0.63 friction coefficient) as a function of the number of sliding cycles. This line suggests 60 percent of a given number of tests can be expected to undergo failure at or before $\sim 3700$ cycles. Given an infinite number of tests, the 90 percent confidence bands were in the region in which the lifetimes of 90 percent of those tests would reside.

The usefulness of a Weibull plot can be demonstrated by relating it to the reliability of a component. For a typical space bearing, which cannot generally be retrieved for maintenance, reliability is very important. If $>99$ percent reliability is desired in a lubricated couple, then the number of cycles that it is allowed to experience should be less than the value that will generally produce failure 1 percent of the time. For the unpassivated samples in figure 6,1 percent of them are predicted to fail by $\sim 120$ th cycles. By comparing each passivation technique's Weibull plot to the plot of the unpassivated specimens (fig. 6), and to each other, produces their relative performance. Their relative performance is summarized after the next section.

\section{Passivated-Lubricated Results}

The Weibull lifetime distributions of the four passivation techniques and the unpassivated technique (from fig. 6) are shown in figure 7. This figure indicates that the predicted lifetimes are all very similar. The 90 percent confidence bands of the five plots (not shown) all overlap over most of the range of each Median Rank Line. Therefore, within 90 percent assurance, it is predicted that no one passivation technique out perform another. These plots indicate that none of the passivation techniques neither exhibited superior nor grossly substandard performances relative to the unpassivated surfaces.

The 1 and 60 percent predicted lifetimes are tabulated in Table III. Again, statistically one cannot say that any one technique out performed another. The possible exception to that may be the 1 percent failure lifetimes. TCP passivated samples have a 1 percent failure of $\sim 1000$ cycles, which is nearly an order of magnitude higher than that of the unpassivated result of $\sim 120$ cycles. This difference is caused by the greater slope (more reproducible data) of the TCP passivated samples. More tests would have to be run to verify this possible distinction.

Given the sliding nature of these tests and the thinness of both the lubricant and the passivation layers, one might have predicted this result. However, the unlubricated tests did show measurable differences between the various techniques. In addition, this same procedure was used to evaluate differences in various ion implanted surfaces (ref. 26). The thicknesses of the implanted layers were on the same order as the thicknesses of the passivated layers. Finally, it has been known for decades that the TCP presoak and the low temperature chromic acid passivation techniques provide additional protection in boundary lubricated contact while lubricated with either mineral oils or esters (refs. 1 to 10 ). Thus, the authors conclude that none of the passivation techniques tested increased the longevity of the perfluoropolyether-lubricated wear couples.

\section{XPS Analysis of the Passivated Surfaces}

By using XPS oxide-to-metal peak area ratios, it was estimated that the oxide film thickness for all the surfaces $\left(\mathrm{Cr}_{x} \mathrm{O}_{y}, \mathrm{Fe}_{\mathrm{x}} \mathrm{O}_{\mathrm{y}}\right.$ or $\left.\mathrm{FePO}_{4}\right)$ was less than $\sim 50 \AA$. A summary of the atomic percent of selective elements obtained from the XPS analysis of a surface passivated using each of the four techniques and the 
unpassivated surface is shown in Table IV. The unpassivated surface had $\mathrm{Cr}$ to Fe ratio of 0.34 , and a distinct carbonaceous contaminating layer as indicated by the $\mathrm{C}$ atomic percent.

The low temperature chromic-acid passivated sample had a high $\mathrm{Cr} / \mathrm{Fe}$ ratio (2.3). This indicates that the passivation solution selectively attacked and dissolved the near-surface iron oxide, while leaving the more inert chromium oxide intact. This would account for the change in $\mathrm{Cr}$ to $\mathrm{Fe}$ ratio in the first few atomic layers of the surface. The higher nitrogen atomic percent on this surface was caused by the presence of nitric acid.

The surface of the sample passivated with the higher temperature chromic-acid solution has a lower $\mathrm{Cr}$ to Fe ratio than the lower temperature chromic-acid passivated surface, but a higher ratio than the unpassivated surface. The difference in the $\mathrm{Cr}$ to $\mathrm{Fe}$ ratios for the two passivation techniques is considered to be within the random error associated with the passivation procedure. It is noted that the two passivation techniques resulted in very similar surface chemistries, which indicates that increasing the passivation time and temperature was relatively ineffective. The fact that the $\mathrm{Cr}$ to $\mathrm{Fe}$ ratio is higher than the unpassivated surface indicates that the $\mathrm{Fe}$ atoms are being selectively removed at a higher rate than the $\mathrm{Cr}$ atoms.

Evidence for iron phosphate formation from TCP passivation is shown in figure 8. The figure compares the XPS spectra of the $\mathrm{Cr}$ region of the high-temperature chromic-acid passivated surface to that of the TCP passivated surface. The chromic-acid passivated surface has a large $\mathrm{Cr}^{\delta+}: \mathrm{Cr}^{\circ}$ metal peak, whereas, the TCP passivated spectra contains a much smaller $\mathrm{Cr}^{\delta+}: \mathrm{Cr}^{\circ}$ metal peak. This, along with the presence of the 12 atomic percent $\mathrm{P}$, and the decreased $\mathrm{Cr}$ to $\mathrm{Fe}$ ratio are consistent with the formation of an iron phosphate surface layer.

As evidenced by a decrease in carbon on the UV/ozone treated surfaces, UV/ozone treatment preferentially removes the carbonaceous contamination layer. UV/ozone treatment was not found to increase the oxide film thickness of these samples. This fact has been previously documented (ref. 30).

\section{SUMMARY OF RESULTS}

1. None of the passivation techniques significantly increased the oxide film thickness.

2. Using x-ray photoelectron spectroscopy, it was found that chromic acid passivation increased the $\mathrm{Cr}$ to Fe ratio of the surface. Couples passivated with chromic acid, tested unlubricated, experienced an improvement in friction coefficient for a short time. However, chromic acid passivation did not affect the PFPE lubricating lifetime.

3. TCP passivation resulted in a few-monolayer-thick $\mathrm{FePO}_{4}$ layer on the surface. TCP passivated couples tested unlubricated experienced improved, low friction for a short duration. However, an improvement in PFPE-lubricating lifetime was not observed after TCP passivation.

4. UV/Ozone treatment removed the carbonaceous contamination layer on the surface but did not alter either the unlubricated or the PFPE-lubricated lifetimes.

5. The PFPE lubricated lifetime of $440 \mathrm{C}$ couples did not definitively change as a result of the various passivation techniques.

\section{REFERENCES}

1. Singer, H.B., "The Effect of TCP Treatment on the Low-Speed Performance of Ball Bearings," MIT/IL E-2317, Sept 1968; presented at the Dartmouth Bearings Conference, Dartmouth College, Hanover, N.H., 3-6 Sept 1968.

2. Allen, S., "Effect of Surface Condition of Instrument Ball Bearings," Proc. Int'l. Conf. Surf. Techn., pp. 566-583, 1973.

3. Singer, H.B., "A Potpourri of Ball Bearing Surface Chemistry Problems," Charles Stark Draper Laboratory, Cambridge, MA, Rept. P-1474, 1982. Presented at the Seventh Contamination Symposium, Sunnyvale, CA, 1982.

4. Murday, J.S., Shafrin, E.G., Kingsbury, E.P., and Allen, S., "Surface Chemistry of Ball Bearing Steels," NRL Memorandum Report 3047, April 1975.

5. Shafrin, E.G., and Murday, J.S., "Auger Compositional Analysis of Ball Bearing Steels Reacted with Tricresyl Phosphate," ASLE Trans., 21, 4, p 329-336, 1978. 
6. Shafrin, E.G., and Murday, J.S., "Analytical Approach to Ball-Bearing Surface Chemistry," J. Vac. Sci. Technol., 14, 1, Jan/Feb 1977.

7. Allen, S., "Final Report, Gyro Bearing Program, Tasks 1 to 6, NAS 9-3079," MIT/DL R-586, June 1970; "Tasks 8 to 10, NAS 9-3079," MIT/DL R-674, Oct 1970.

8. Woodwell, R.G., Miller, L., and Anderson, C., "Alkaline Cleaning: Its Effects on Tricresyl Phosphate Coated Bearing Steels," presented at the Non-Ozone Depleting Chemical Cleaning and Lubrication of Space System Mechanical Components for Multi-Year Operations, Pub. No. S69-5762-1.0-1, Sept 26-27, 1994.

9. Edwards, A.C., "Final Report on the Gyro Spin-Axis Bearing Program," MIT/IL R-418, Sept 1963.

10. Hannan, C.H., "The Effect of Tri-Cresyl-Phosphate Coating on Reducing Torques in Low-Speed Bearings," presented at the Dartmouth Bearings Conference, Dartmouth College, Hanover, N.H., 3-6 Sept 1968.

11. Jones, W.R., Jr., "Properties of Perfluoropolyethers for Space Applications," Trib. Trans., 38, 3, 557, (1995).

12. Fleischauer, P.D., and Hilton, M.R., "Assessment of the Tribological Requirements of Advanced Spacecraft Mechanisms," TOR-0090(5064)-1, (1991).

13. Rowntree, R.A., and Todd, M.J., "A Review of European Trends in Space Tribology and Its Application to Spacecraft Mechanism Design," Mat. Res. Soc. Symp. Proc., 140, 21-34, (1989).

14. Watson, N.D., Miller, J.B., Taylor, L.V., Lovell, J.B., Cox, L.W., Fedors, J.C., Kopia, L.P., Holloway, R.M., and Bradley, O.H., "Earth Radiation Budget Experiment (ERBE) Scanner Instrument Anomaly Investigation," NASA TM-87636, (1985).

15. Conley, P.L. And Bohner, J.J., "Experience with Synthetic Fluorinated Fluid Lubricants," 24th Aerospace Mech. Sympl, NAS CP $-062,213,1990$.

16. Herrera-Fierro, P., Jones, W.R., Jr., and Pepper, S.V., "Interfacial Chemistry of a Perfluoropolyether Lubricant Studied by X-ray Photoelectron Spectroscopy and Temperature Desorption Spectroscopy," J. Vac. Sci. Technol. A, 2, 11, (Mar/Apr 1993).

17. Carré, D.J., "Perfluoropolyalkylether Oil Degradation: Inference of $\mathrm{FeF}_{3}$ Formation on Steel Surfaces Under Boundary Conditions," ASLE Trans., 29, 2, 121-125, (1986).

18. Hayashida, K., Yamamoto, K., and Nishimura, M., "Wear and Degradation Characteristics of Perfluoroalkylpolyethers (PFPEs) in High Vacuum," Trib. Trans., 37, 1, 196-200, (1994).

19. Carré, D.J., "The Use of Solid Ceramic and Ceramic Hard-Coated Components to Prolong the Performance of Perfluoropolyalkylether Lubricants," Surf. and Coat. Tech., 43/44, 606-617, (1990).

20. Carré, D.J., "The Performance of Perfluoropolyalkyethers Under Boundary Conditions," Trib. Trans., 31, 4, 437-441, (1988).

21. Mori, S., and Morales, W., "Tribological Reactions of Perfluoroalkylpolyether Oils with Stainless Steel Under Ultrahigh Vacuum Conditions at Room Temperature," Wear, 132, 111-121, (1989).

22. Kasai, P.H., "Perfluoropolyethers: Intramolecular Disproportionation," Macromolecules, 25, 6791-6799, (1992).

23. Carré, D.J., and Markowitz, J.A., "The Reaction of Perfluoropolyalkylether Oil with $\mathrm{FeF}_{3}, \mathrm{AlF}_{3}$, and $\mathrm{AlCl}_{3}$ at Elevated Temperatures," ASLE Trans., 28, 1, 40-46, (1985). 
24. Jones, W.R., Jr., Paciorek, K.J.L., Harris, D.H., Smythe, M.E., Nakahara, J.H., and Kratzer, R.H., "The Effects of Metals and Inhibitors on Thermal Oxidative Degradation Reactions of Unbranched Perfluoroalkyl Ethers," R. H. Ind. Eng. Chem. Prod. Res. Dev., 24, p 417-420, (Sept. 1985).

25. Morales, W., "Perfluoropolyalkylether Decomposition on Catalytic Aluminas," NASA TM-106547, (Apr 1994).

26. Shogrin, B., Wilbur, P.J., Jones, W.R., Jr., Herrera-Fierro, P., and Williamson, D.L., "The Effects of Ion Implantation on the Tribology of Perfluoropolyether-Lubricated 440C Stainless Steel Couples," Tribology Transactions, 39, 3, 507-516, 1996.

27. Wedeven, L.D. and Goodell, A.J., "Evaluation of Passivated and TCP Treated 440C Surfaces with WA Machine," Wedeven and Assoc., Subcontract No. SS-274275-J, (Sept. 1991).

28. Singer, H.B., "The Effect of TCP Treatment on the Low Speed Performance of Ball Bearings," E-2317, Instrument Laboratory, Massachusetts Institute of Technology, (Sept. 1968).

29. Arezzo, F. and Moore, R.L., "Reactions Between 52100 Steel and Tricresyl Phosphate Neat and Mixed with Hydrocarbon Oil," Surface and Coating Technology, 33, 235-242, (1987).

30. Vig, J.R., "UV/Ozone Cleaning of Surfaces," SLCET-TR-86-6, (May 1986).

31. Scarati, A.M., and Caporiccio, G., "Frictional Behaviour and Wear Resistance of Rigid Disks Lubricated with Neutral and Functional Perfluoropolyethers," IEEE Trans. on Magnetics, Mag.-23, 1, 106-108, (Jan. 1987).

32. Pepper, S.V., "Characterization and Application of a Grazing Angle Objective for Quantitative Infrared Reflection Spectroscopy," Appl. Spect., 49, 3, 354-360, (March 1995).

33. Johnson, L.G., The Statistical Treatment of Fatigue Exper., Elsevier Publishing Company, Inc., (1964).

TABLE 1. - SELECTED PROPERTIES OF THE PFPE USED IN THE STUDY

\begin{tabular}{|c|c|}
\hline Average Molecular Weight & $11000 \mathrm{amu}$ \\
\hline $\begin{aligned} & \text { Vapor Pressure } \text { at } 20^{\circ} \mathrm{C} \\
& \text { at } 50^{\circ} \mathrm{C} \\
& \text { at } 100^{\circ} \mathrm{C} \\
&\end{aligned}$ & $\begin{array}{r}3 \times 10^{-14} \text { Torr } \\
2 \times 10^{-12} \text { Torr } \\
1 \times 10^{-9} \text { Torr }\end{array}$ \\
\hline $\begin{aligned} \text { Kinematic Viscosity } & \text { at } 20^{\circ} \mathrm{C} \\
& \text { at } 50^{\circ} \mathrm{C} \\
& \text { at } 100^{\circ} \mathrm{C}\end{aligned}$ & $\begin{array}{c}2717 \mathrm{~mm}^{2} / \mathrm{s} \text { (centistoke) } \\
444 \mathrm{~mm} 2 / \mathrm{s} \\
63 \mathrm{~mm}^{2} / \mathrm{s}\end{array}$ \\
\hline $\begin{array}{ll}\text { Density } & \text { at } 20^{\circ} \mathrm{C} \\
& \text { at } 50^{\circ} \mathrm{C} \\
& \text { at } 100^{\circ} \mathrm{C}\end{array}$ & $\begin{array}{l}1.92 \mathrm{~g} / \mathrm{cm}^{3} \\
1.87 \mathrm{~g} / \mathrm{cm}^{3} \\
1.78 \mathrm{~g} / \mathrm{cm}^{3}\end{array}$ \\
\hline Surface Tension at $25^{\circ} \mathrm{C}$ & 19 dynes $/ \mathrm{cm}$ \\
\hline
\end{tabular}

Table II.-UNLUBRICATED WEAR TEST RESULTS

\begin{tabular}{|c|c|c|c|}
\hline $\begin{array}{c}\text { Surface passivation } \\
\text { treatment }\end{array}$ & $\begin{array}{c}\text { Initial mean friction } \\
\text { coefficient }\end{array}$ & $\begin{array}{c}\text { Number of } \\
\text { cycles until } \\
\text { failure }\end{array}$ & $\begin{array}{c}\text { Tracks } \\
\text { tested }\end{array}$ \\
\hline $\begin{array}{c}\text { Chromic-acid, } \\
\text { low temperature }\end{array}$ & $0.27(0.24-0.27)$ & $5(4$ to 6$)$ & 5 \\
\hline $\begin{array}{c}\text { Chromic-acid, } \\
\text { high temperature }\end{array}$ & $0.26(0.24-0.27)$ & $9(7$ to 10) & 4 \\
\hline Tricresyl phosphate & $0.29(0.27-0.34)$ & $68(60$ to 85$)$ & 5 \\
\hline
\end{tabular}


TABLE III-SUMMARY OF DATA OBTAINED FROM WEIBULL PLOTS

\begin{tabular}{|l|c|c|}
\hline \multicolumn{1}{|c|}{$\begin{array}{c}\text { Surface } \\
\text { passivation/treatment }\end{array}$} & $\begin{array}{c}1 \text { percent } \\
\text { failure }\end{array}$ & $\begin{array}{c}60 \text { percent } \\
\text { failure }\end{array}$ \\
\hline Unpassivated & 120 & 3700 \\
\hline $\begin{array}{l}\text { Chromic-acid, } \\
\text { low temperature }\end{array}$ & 440 & 3600 \\
\hline $\begin{array}{l}\text { Chromic-acid, } \\
\text { high temperature }\end{array}$ & 440 & 7000 \\
\hline Tricresyl phosphate & 1000 & 2300 \\
\hline Uv/Ozone treatment & 240 & 5000 \\
\hline
\end{tabular}

TABLE IV.-ELEMENTAL SURFACE CONCENTRATION FOR EACH PASSIVATION TREATMENT OBTAINED BY XPS

\begin{tabular}{|l|c|c|c|c|c|c|}
\hline \multicolumn{1}{|c|}{ Atom percent } & $\mathrm{C}$ & $\mathrm{O}$ & $\mathrm{Fe}$ & $\mathrm{Cr}$ & $\begin{array}{c}\mathrm{Cr} / \mathrm{Fe} \\
\text { Ratio }\end{array}$ & Miscellaneous \\
\hline Unpassivated & 28 & 54 & 13 & 4.4 & 0.34 & $0.5 \mathrm{~N}$ \\
\hline $\begin{array}{l}\text { Chromic-acid, } \\
\text { low temperature }\end{array}$ & 23 & 61 & 4.3 & 10 & 2.3 & $0.9 \mathrm{~N}$ \\
\hline $\begin{array}{l}\text { Chromic-acid, } \\
\text { high temperature }\end{array}$ & 19 & 61 & 10.1 & 9.3 & 0.93 & $0.9 \mathrm{~N}$ \\
\hline \begin{tabular}{l} 
Tricresyl phosphate \\
\hline
\end{tabular} & 24 & 58 & 4.6 & 1.1 & 0.24 & $\begin{array}{c}0.8 \mathrm{Na} \\
3.5 \mathrm{Ca} \\
12 \mathrm{P}\end{array}$ \\
\hline UV/Ozone treatment & 18 & 58 & 18 & 6 & 0.33 & $<0.1 \mathrm{~N}$ \\
\hline
\end{tabular}




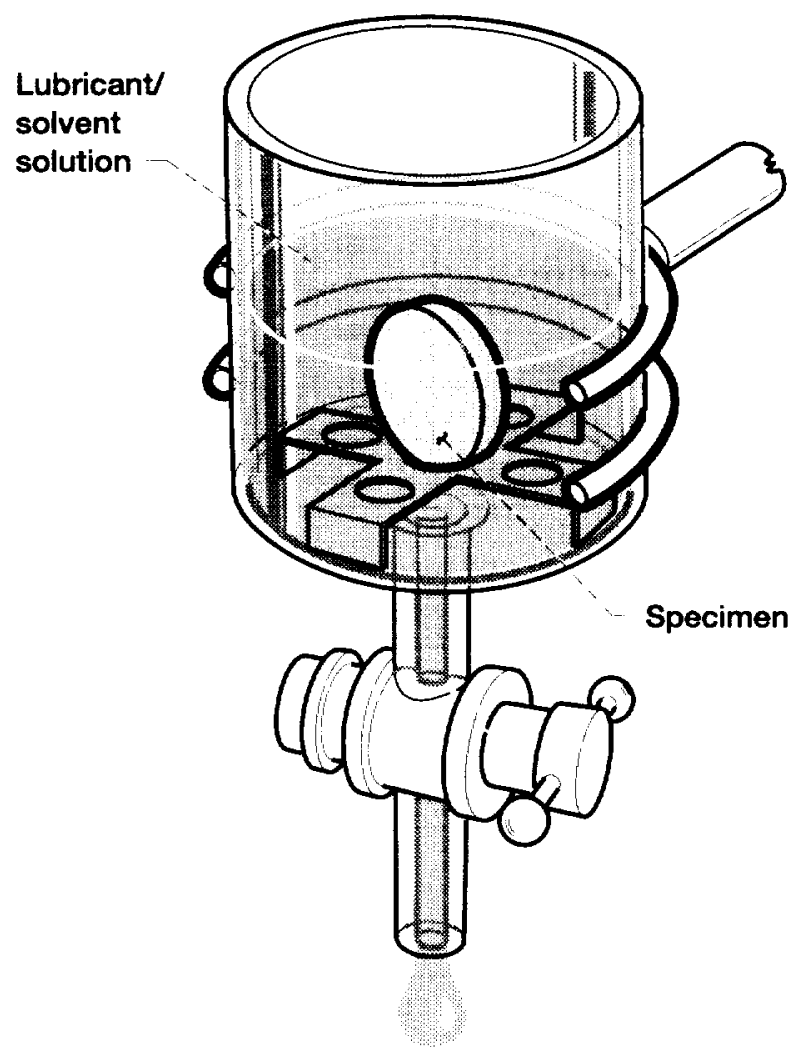

Figure 1.-Film deposition device (FDD).

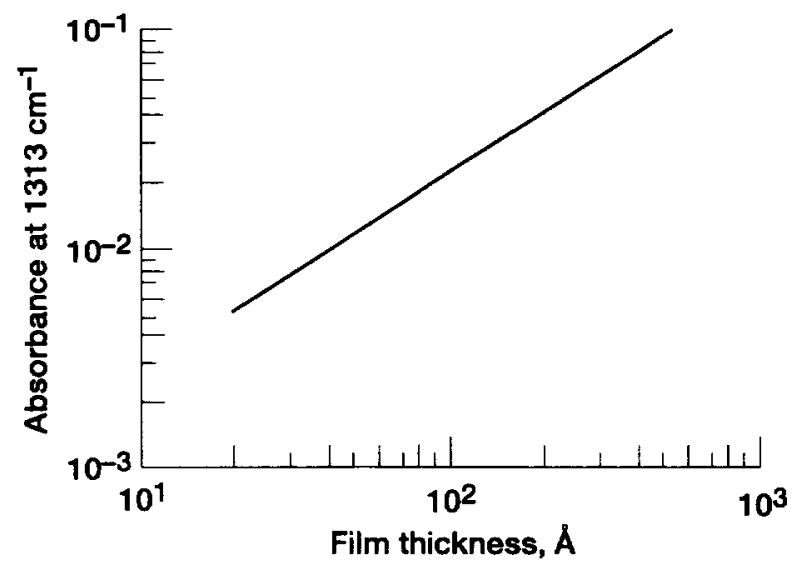

Figure 2.-Calculated IR absorbances for the $1313 \mathrm{~cm}^{-1}$ band of HFPO as a function of film thickness. 


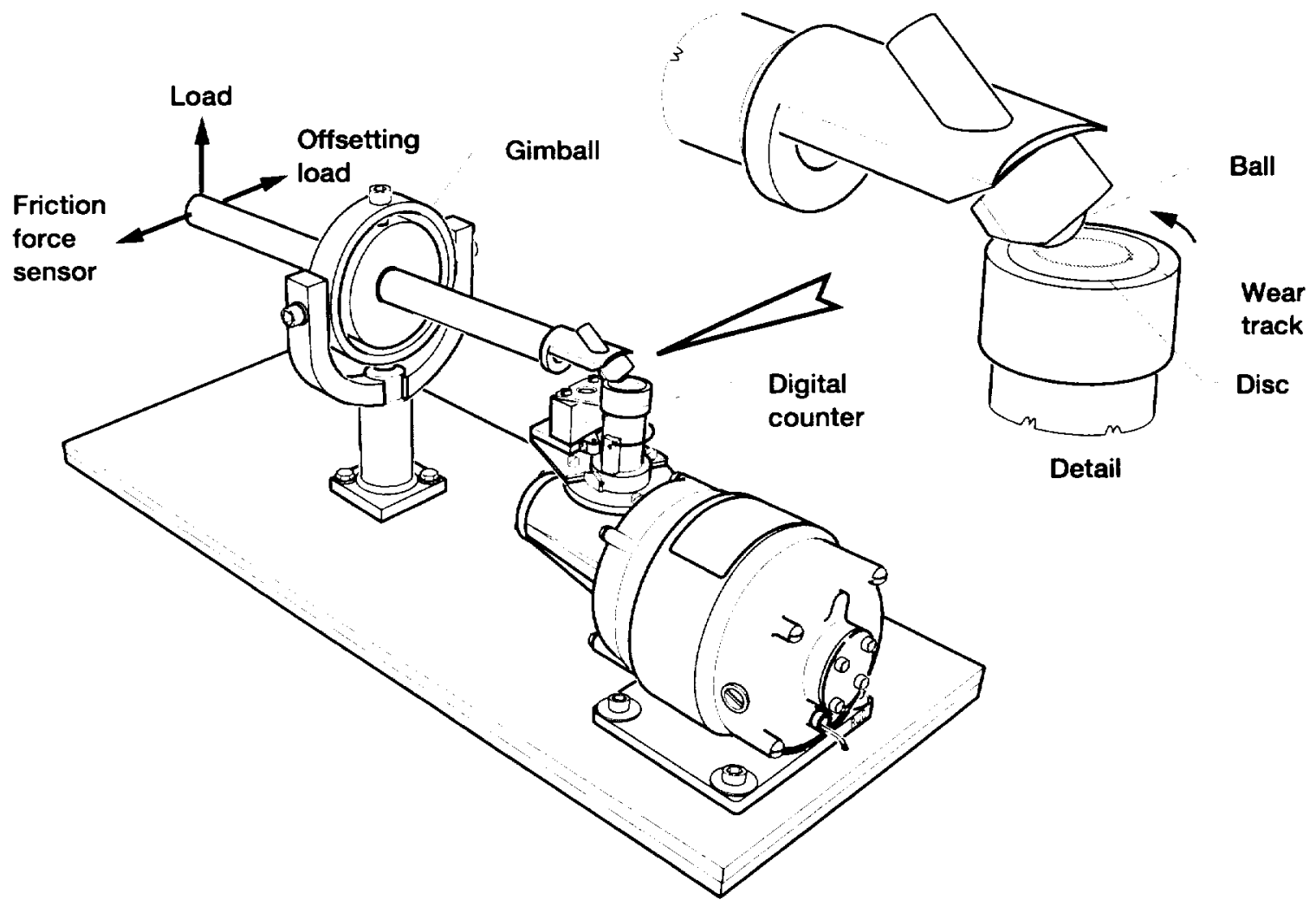

Figure 3.-Ball-on-disc tribometer.

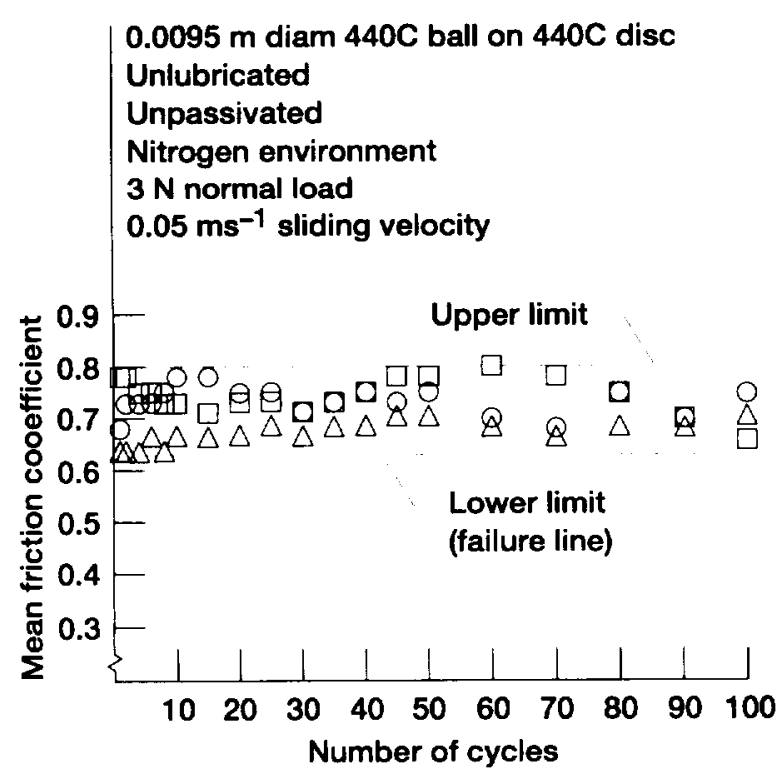

Figure 4.-Typical friction coefficient data for unpassivated, unlubricated disc/ball couples (ref. 26).

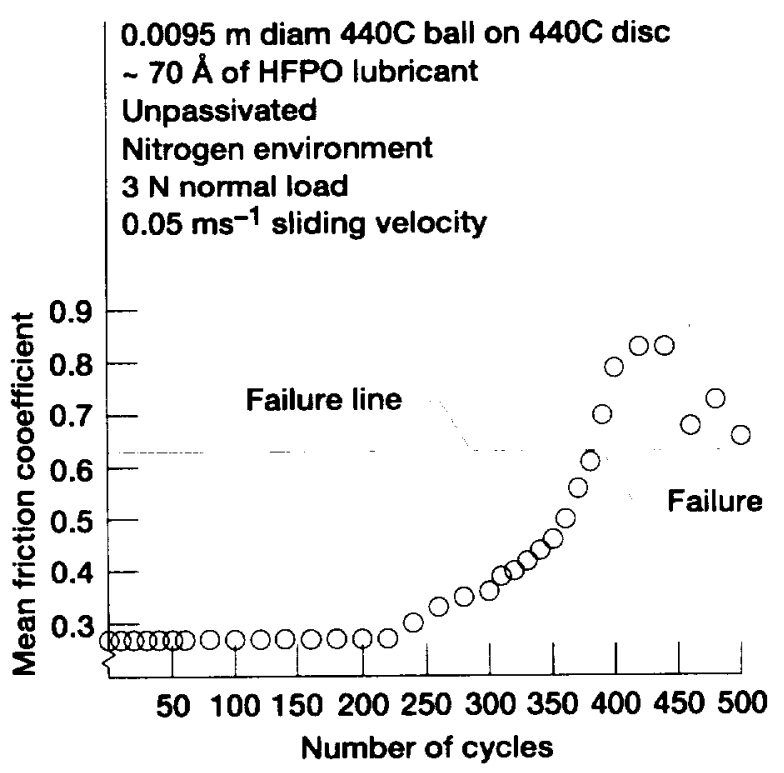

Figure 5.-Typical friction coefficient data for unpassivated, lubricated disc/ball couples (ref. 26). 


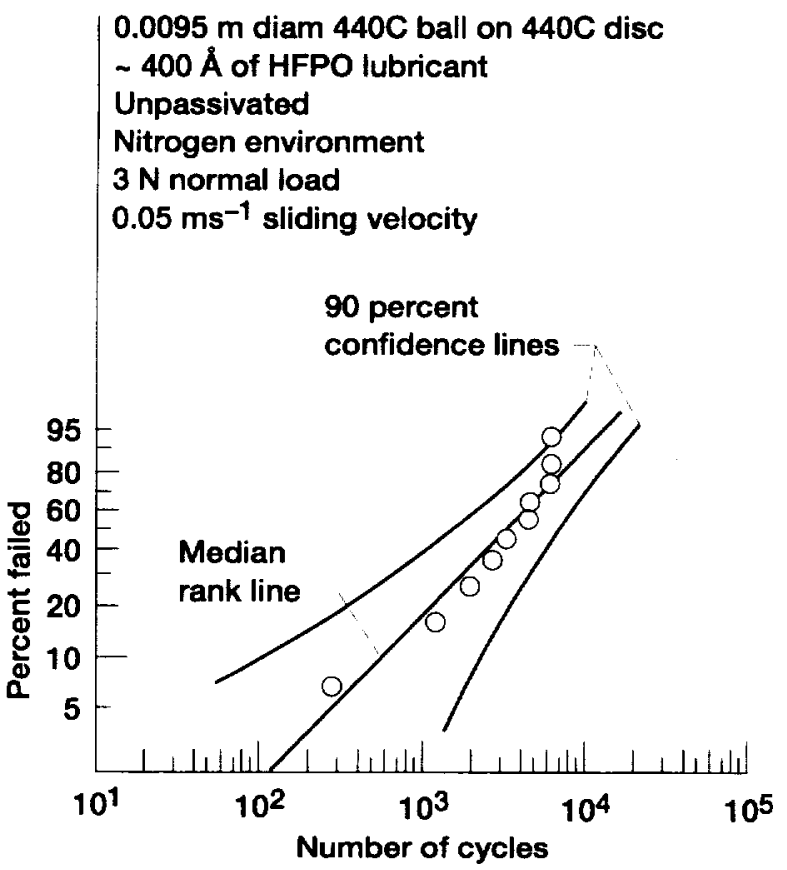

Figure 6.-Weibull distribution lifetimes for unpassivated, lubricated disc/ball couples.

$0.0095 \mathrm{~m}$ diam $440 \mathrm{C}$ ball on $440 \mathrm{C}$ disc $\sim 400 \AA$ of HFPO lubricant Nitrogen environment $3 \mathrm{~N}$ normal load $0.05 \mathrm{~ms}^{-1}$ sliding velocity

$\square$ Unpassivated

$\triangleright$ Chromic acid, low temperature

$\diamond$ Chromic acid, high temperature

- TCP

O UV/ozone

Chromic acid, high temperature

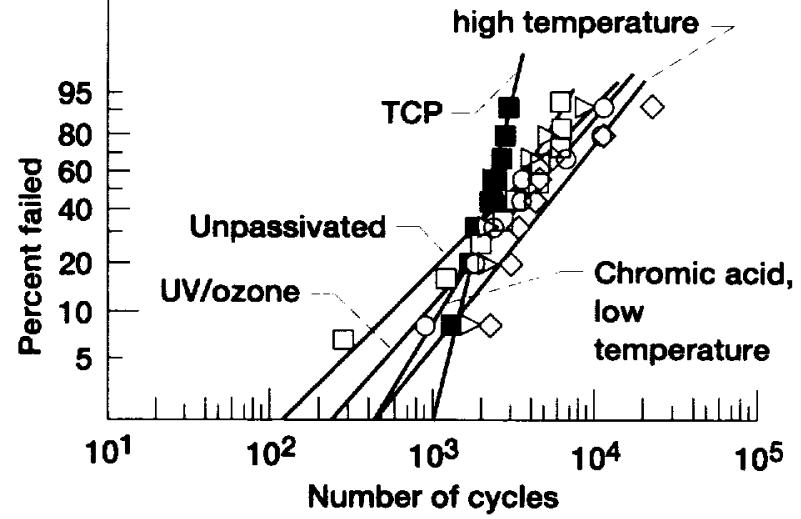

Figure 7.-Effect of passivation on Weibull distribution lifetimes for lubricated disc/ball couples.

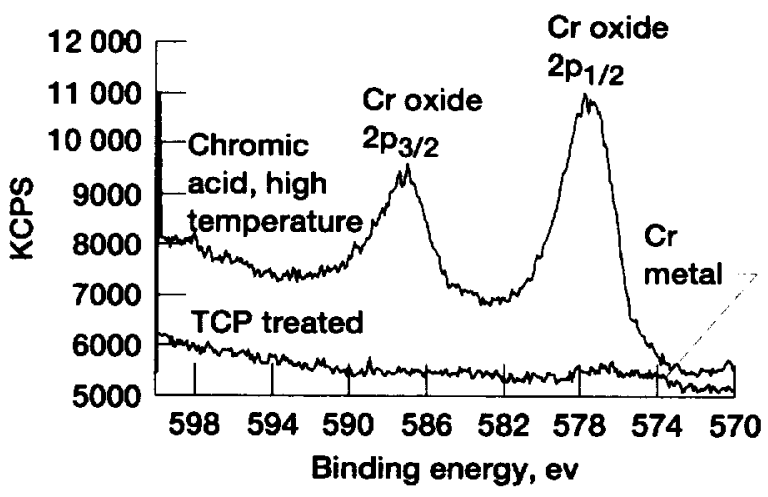

Figure 8.-XPS spectra showing the chromium oxide region of both the high temperature chromic-acid, and TCP passivated surfaces. 

Public reporting burden for this collection of information is estimated to average 1 hour per response, including the time for reviewing instructions, searching existing data sources, gathering and maintaining the data needed, and completing and reviewing the collection of information. Send comments regarding this burden estimate or any other aspect of this collection of information, including suggestions for reducing this burden, to Washington Headquarters Services, Directorate for Information Operations and Peports, 1215 Jefferson Davis Highway, Suite 1204, Artington, VA 22202-4302, and to the Office of Management and Budget, Paperwork Reduction Project (0704-0188), Washington, DC 20503.

\section{AGENCY USE ONLY (Leave blank) 1 2. REPORT DATE}

July 1997

\section{TITLE AND SUBTITLE}

The Effects of Acid Passivation, Tricresyl Phosphate Pre-Soak, and UV/Ozone

Treatment on the Tribology of Perfluoropolyether-Lubricated $440 \mathrm{C}$ Stainless Steel Couples

6. AUTHOR(S)

\section{REPORT TYPE AND DATES COVERED}

Technical Memorandum

5. FUNDING NUMBERS

Bradley A. Shogrin, William R. Jones, Jr., and Pilar Herrera-Fierro

WU-274-00-00

7. PERFORMING ORGANIZATION NAME(S) AND ADDRESS(ES)

B. PERFormING ORGANIZATION REPORT NUMBER

National Aeronautics and Space Administration

Lewis Research Center

Cleveland, Ohio 44135-3191

E-10805

9. SPONSORING/MONITORING AGENCY NAME(S) AND ADDRESS(ES)

10. SPONSORINGMONITORING AGENCY REPORT NUMBER

National Aeronautics and Space Administration

Washington, DC 20546-0001

NASA TM-107503

11. SUPPLEMENTARY NOTES

Prepared for the Annual Meeting sponsored by the Society of Tribologists and Lubrication Engineers, Kansas City, Missouri, May 18-22, 1997. Bradley A. Shogrin, Case Western Reserve University, Cleveland, Ohio (work funded under NASA Cooperative Agreement NCC-409); William R. Jones, Jr., NASA Lewis Research Center; and Pilar Herrera-Fierro, Ohio Aerospace Institute, Cleveland, Ohio. Responsible person, William R. Jones Jr., organization code 5140, (216) 433-6051.

\begin{tabular}{|l|l}
\hline 12a. DISTRIBUTION/AVAILABILITY STATEMENT & 12b. DISTRIBUTION CODE
\end{tabular}

Unclassified - Unlimited

Subject Category 27

This publication is available from the NASA Center for AeroSpace Information, (301) 621-0390.

13. ABSTRACT (Maximum 200 words)

The boundary-lubrication performance of perfluoropolyether (PFPE) thin films in the presence of passivated $440 \mathrm{C}$ stainless steel is presented. The study utilized a standard ball-on-disc tribometer. Stainless steel surfaces were passivated with one of four techniques: 1) submersion in a chromic acid bath for 30 minutes at $46{ }^{\circ} \mathrm{C}, 2$ ) submersion in a chromic acid bath for 60 minutes at $56^{\circ} \mathrm{C}, 3$ ) submersion in a tricresyl phosphate (TCP) bath for 2 days at $107^{\circ} \mathrm{C}$, or 4 ) UV/Ozone treated for 15 minutes. After passivation, each disc had a $400 \AA$ film of PFPE (hexafluoropropene oxide) applied to it reproducibly $( \pm 20 \%)$ and uniformly $( \pm 15 \%)$ using a film deposition device. The lifetimes of these films were quantified by measuring the number of sliding wear cycles required to induce an increase in the friction coefficient from an initial value characteristic of the lubricated wear couple to a final, or failure value, characteristic of an unlubricated, unpassivated wear couple. The lubricated lifetime of the $440 \mathrm{C}$ couple was not altered as a result of the various passivation techniques. The resulting surface chemistry of each passivation technique was examined using X-ray photoelectron spectroscopy (XPS). It was found that chromic acid passivation altered the $\mathrm{Cr}$ to $\mathrm{Fe}$ ratio of the surface. TCP passivation resulted in a $\mathrm{FePO}_{4}$ layer on the surface, while UV/Ozone passivation only removed the carbonaceous contamination layer. None of the passivation techniques were found to dramatically increase the oxide film thickness.

\begin{tabular}{|c|c|c|}
\hline \multicolumn{3}{|c|}{$\begin{array}{l}\text { 14. SUBJECT TERMS } \\
\text { Boundary lubrication; Perfluoropolyethers; Passivation }\end{array}$} \\
\hline $\begin{array}{l}\text { 17. SECURITY CLASSIFICATION } \\
\text { OF REPORT } \\
\text { Unclassified }\end{array}$ & $\begin{array}{l}\text { 18. SECURITY CLASSIFICATION } \\
\text { OF THIS PAGE } \\
\text { Unclassified }\end{array}$ & $\begin{array}{l}\text { 19. SECURITY CLASSIFICATION } \\
\text { OF ABSTAACT } \\
\text { Unclassified }\end{array}$ \\
\hline
\end{tabular}

NSN 7540-01-280-5500 